\title{
Regulation of peri-attachment embryo development in the golden hamster: role of growth factors
}

\author{
P.B. Seshagiri *, A. Mishra, G. Ramesh, R.P. Rao \\ Department of Molecular Reproduction, Development and Genetics, Indian Institute of Science, \\ Bangalore 560 012, India
}

Received 30 March 2001; accepted 16 April 2001

\begin{abstract}
The molecular regulation of mammalian peri-implantation development is complex and difficult to study in vivo. We successfully cultured hamster blastocysts through hatching and peri-attachment stages, using a chemically defined medium, HECM-2h. Using this system, we showed that a species-specific, embryonic cysteine-like protease is involved in blastocyst hatching and that the process is modulated by growth factors. In particular, heparin binding-epidermal growth factor (HB-EGF) or leukemia inhibitory factor (LIF) enhance blastocyst hatching, and the former also improves attachment and trophoblast outgrowth. We observed interesting changing patterns of expression of mRNA and/or immunoreactive protein for EGF, HB-EGF, LIF and transforming growth factor- $\beta$ (TGF- $\beta$ ) in the embryo and/or endometrial tissue, during peri-implantation development. Together, it appears that hamster blastocyst hatching, attachment and trophoblast outgrowth are regulated by autocrine and/or paracrine growth factors, produced by the embryo-endometrial tissues. (C) 2002 Elsevier Science Ireland Ltd. All rights reserved.
\end{abstract}

Keywords: Blastocyst development; Growth factors; Hamster; Hatching; Protease

* Corresponding author. Tel.: + 91-80-309-2687; fax: +91-80-360-0999.

E-mail address: polani@mrdg.iisc.ernet.in (P.B. Seshagiri).

0165-0378/02/\$ - see front matter (C) 2002 Elsevier Science Ireland Ltd. All rights reserved. PII: S0165-0378(01)00086-9 


\section{Introduction}

During mammalian embryogenesis, the zygote undergoes a series of changes forming a blastocyst. Prior to implantation (attachment) into the uterine endometrium, the blastocyst hatches from its zona pellucida (zona). These peri-implantation events are rate limiting and critical for the establishment of pregnancy. Low implantation rates of in vitro fertilized (IVF) human embryos are largely due to impaired development and hatching of blastocysts (Magli et al., 1998). Little, however, is known about their molecular regulation, primarily because of difficulties in studying them in vivo. For this, in vitro embryo development models are necessary, but they are constrained by inadequacies of culture systems, in particular, the suboptimal culture media and the low percentage development of hatched and attached blastocysts from cleavage-stage embryos (Bavister, 1995; Seshagiri et al., 1999).

To study peri-attachment embryo development, the golden hamster is one of the useful models. Because preimplantation development can be achieved using chemically defined culture media and cleavage-stage embryos are extremely sensitive to culture conditions (Seshagiri and Bavister, 1989a,b, 1991a,b; McKiernan and Bavister, 1990; Bavister, 1995; Mishra and Seshagiri, 1998), hamster embryos could be exploited to test media components and regulators on peri-implantation development. Moreover, the mechanism of hatching (Kane and Bavister, 1988a,b; Gonzales and Bavister, 1995; Gonzales et al., 1996; Mishra and Seshagiri, 1998) and the hormonal requirement for implantation (Evans and Kennedy, 1980) are quite different in this species, compared to other mammals. In this article, we summarize the past and ongoing research efforts to understand early hamster development.

\section{Development of blastocysts through peri-attachment stages}

In the last decade, extensive attempts were made by systematically optimizing physiochemical and media components to achieve normal and viable in vitro development of hamster preimplantation embryos (Seshagiri and Bavister, 1989a,b, 1991a,b; McKiernan and Bavister, 1990; Barnett and Bavister, 1992; Seshagiri et al., 1999). An important discovery has been the detrimental effect of glucose and inorganic phosphate on embryo development (Schini and Bavister, 1988; Seshagiri and Bavister, 1989a,b, 1991a). For supporting development of 8-cell embryos to blastocysts, hamster embryo culture medium (HECM)-2 was formulated (Seshagiri and Bavister, 1989b). By supplementing $0.5 \mathrm{mM}$ succinate and $0.01 \mathrm{mM}$ malate to 
HECM-2, 100\% development of high quality, biologically viable blastocysts was achieved (Ain and Seshagiri, 1997). This, however, failed to support blastocyst hatching. Interestingly, supplementation of succinate, amino acids, vitamins (inositol, pantothenate, choline chloride) and bovine serum albumin (BSA) to HECM-2 supported 100\% development of hatched blastocysts (Fig. 1) and this new medium was designated as HECM-2h; h, hatching (Mishra and Seshagiri, 1998).

In HECM-2h, all blastocysts deflated and hatched from focally lysed zonae, which underwent complete dissolution (Fig. 1). Omission of BSA from HECM-2h failed to support hatching, while that of vitamins reduced it (Mishra and Seshagiri, 1998). Blastocysts, having the potential to undergo hatching in HECM-2h, were of high quality as they had higher mean cell number (MCN) than that of blastocysts developing in BSA-free HECM-2h. Besides, the MCN of cultured blastocysts was superior to that of in vivo developed blastocysts $(35.2 \pm 1.6$ vs. $17.6 \pm 1.0, P<0.001$; Mishra and Seshagiri, 1998). Cell allocation, i.e., trophectoderm (TE) to inner cell mass

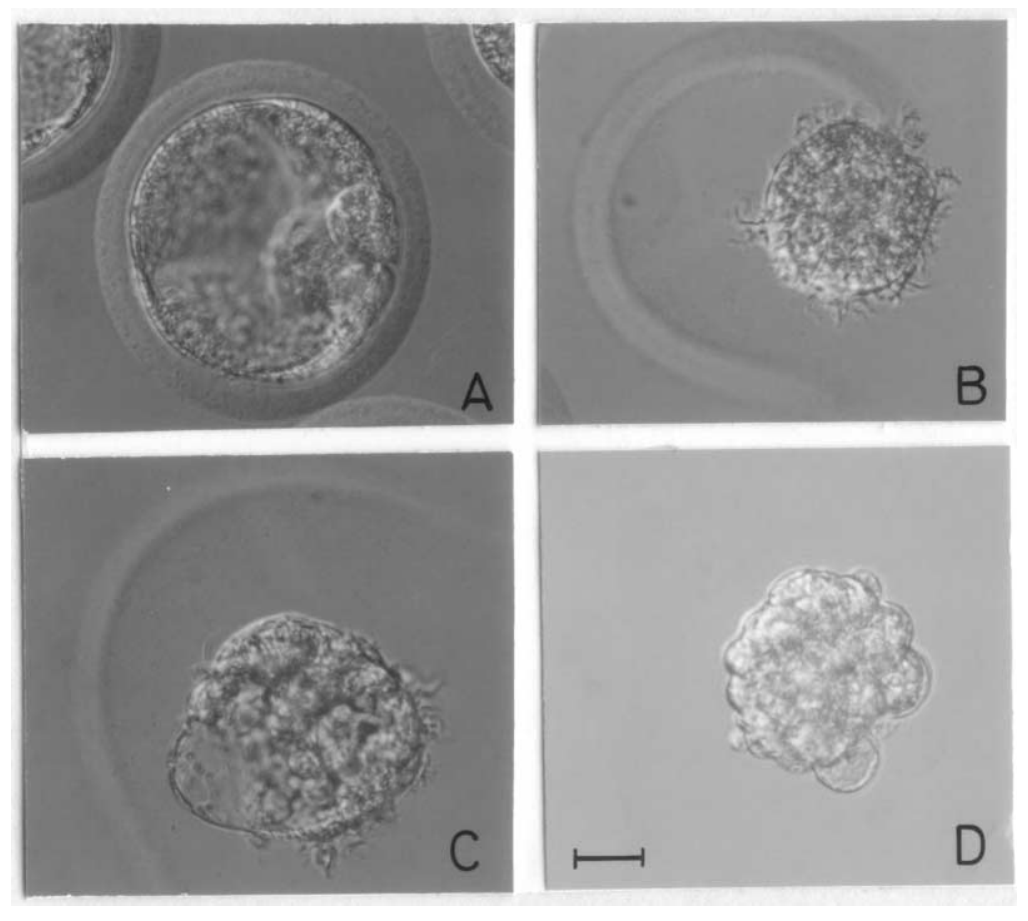

Fig. 1. Photomicrographs of cultured zona-intact hamster blastocyst (A), blastocysts undergoing zona lysis (B, C) and an azonal blastocyst (D). Note the partial (B, C) or complete (D) disappearance of zona and also bristle-like trophoectodermal projections on the periphery of embryos $(B, C)$. Bar $=25 \mu \mathrm{m}$. (Photographed with Nomarski optics, $\times 20$ ). 
(ICM) ratio in blastocysts, remained unaltered in both media (Mishra and Seshagiri, 1998). But HECM-2h neither supported attachment of hatched blastocysts nor trophoblast (TB) outgrowth. Surprisingly, when $10 \%$ bovine fetal serum (BFS) was supplemented to HECM-2h, it was detrimental to the development of blastocysts and none of them hatched. Interestingly, however, BFS was required either as a supplement to HECM-2h or as a coating on dishes for azonal blastocysts to efficiently attach and exhibit TB outgrowth (Mishra and Seshagiri, 1998; Seshagiri et al., 1999). It appears that serum supplementation to culture medium has a differential effect on hamster embryo development, depending on the stage of embryos exposed to serum.

\section{Blastocyst hatching and involvement of embryonic protease}

The phenomenon of hamster blastocyst hatching, both in vivo and in vitro (Kane and Bavister, 1988a,b; Gonzales and Bavister, 1995; Gonzales et al., 1996; Mishra and Seshagiri, 1998), has been studied. Unlike those in other species, hamster blastocyst hatching mechanisms observed in vitro are distinct and closely mimic those in vivo. These include $100 \%$ blastocysts development and hatching; blastocysts undergoing deflation followed by a focal zona thinning preceding focal zona rupture and embryos then crawling out of the hemizona case, accompanied by a complete zona dissolution (Fig. 1); and azonal blastocysts efficiently attaching and exhibiting trophoblast outgrowth. Moreover, preblastocyst-stage embryos also exhibit zona lysis. In this regard, the culture medium, HECM-2h appears to be the best so far as the in vitro development of peri-attachment hamster blastocysts is concerned (Mishra and Seshagiri, 1998). Unlike in hamsters, in the mouse/rat (Bergstrom, 1972; Surani, 1975; Seshagiri et al., 1999), cow (Massip and Mulnard, 1980), rhesus monkey (Seshagiri and Hearn, 1993) and human (Lopata and Hay, 1989), hatching occurs by a different mechanism. Fully expanded blastocysts exert hydrostatic (mechanical) pressure creating a nick in the zona, through which they egress, leaving the empty zona intact. Moreover, evidence for the source of zona lytic protease has been equivocal. Both blastocysts (Denker and Fritz, 1979; Perona and Wassarman, 1986; Menino and Williams, 1987; Sawada et al., 1990; Vu et al., 1997) and uterus (Joshi and Murray, 1974; Denker, 1977) have been shown to produce zona lysin.

In hamsters, the complete dissolution of zona during blastocyst hatching observed in vitro strongly indicates a potent zona lytic factor of embryonic origin. Unequivocal lines of evidence to support this are the following. When freshly recovered 2-cell embryos were co-cultured with hatching-blas- 
tocysts, the former exhibited partial/complete zona lysis; also, co-cultured pre-morula (1-8-cell) stage embryos. However, zonae from mice, rats, sheep and humans were resistant to lysis, indicating that the hamster zona lysin could be species-specific (Mishra and Seshagiri, 2000a). Unlike from other species, zonae from hamsters were found to be extraordinarily susceptible to pronase. Interestingly, cysteine protease inhibitors, viz., antipain, leupeptin, E-64 and $p$-hydromercuribenzoate, completely inhibited hatching of cultured blastocysts without affecting their development, while inhibitors to other types of proteases had either modest or no curtailment of hatching. Moreover, the chemical means of zona dissolution, for example, by reactive oxygen species (ROS), appeared unlikely, since cultured blastocysts exhibited zona lysis despite the presence of superoxide dismutase or catalase, scavengers of ROS (Mishra and Seshagiri, 2000a). These observations show that blastocyst-derived zona lytic protease(s) is responsible for hatching in hamsters. However, the cell type producing this activity and its regulation remain to be investigated (see below).

We believe that uterine zona lysin involvement in blastocyst hatching in vivo is either minimal or negligible in hamsters since (i) luminal flushings and endometrial extracts from day 4 (=zona escape in vivo) pregnant females fail to lyse zonae in vitro; and (ii) transferred 2-cells or blastocysts to uterus of day 3 pseudopregnant females fail to exhibit zona escape, despite residing in the uterus for $12 \mathrm{~h}$ (Mishra and Seshagiri, 2000a). Taken together, these observations indicate the existence of species-specific, blastocyst-derived potent proteolytic factor(s), with a cysteine protease like activity, responsible for hatching of hamster blastocysts.

\section{Role of growth factors during peri-attachment development}

A number of studies document growth factors having embryotrophic effects (Paria and Dey, 1990; Harvey et al., 1995; Kane et al., 1997; Sargent et al. 1998); others, such as chemokines, cytokines, adhesion molecules and proteinases in peri-implantation development (Kauma, 2000; Simon et al., 1996). Because striking features are observed with development and hatching of blastocysts (Gonzales and Bavister, 1995; Mishra and Seshagiri, 1998, 2000a; Seshagiri et al., 1999), and virtually nothing is known about the role of growth factors in hamster development, we studied the involvement of epidermal growth factor (EGF), heparin binding-EGF (HB-EGF), transforming growth factor- $\beta$ (TGF- $\beta$ ) and leukemia inhibitory factor (LIF) during hamster peri-attachment development. We chose them since they have been shown to be important regulators of development of blastocysts and implantation in other systems (Harvey et al., 1995; Simon et al., 1996; Sargent et al., 1998). 


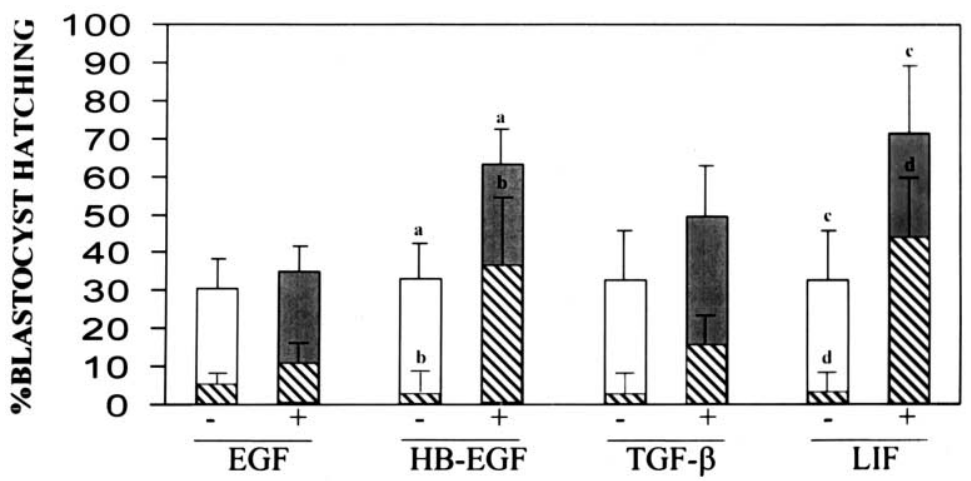

Fig. 2. Influence of growth factors, EGF, HB-EGF, TGF- $\beta$ and LIF on hamster blastocyst hatching. Values shown are mean \pm SEM for six replicate experiments each with a minimum of 40-45 embryos per treatment. The bars represent total hatching, i.e. partial and complete zona lysis, and the hatched portions in each bar represent complete zona lysis. Values with identical superscripts differ significantly $(P<0.05)$. Values corresponding to HB-EGF are reproduced from Mishra and Seshagiri (2000b) with permission from Reproductive Health Care Ltd., UK.

Supplementation of any of the factors, viz., EGF, HB-EGF, TGF- $\beta$ and LIF or their respective antibodies, to HECM-2h did not influence blastocyst development over the untreated control; all treatments showed blastocyst development in the range of $89-99 \%$ of control. Addition of growth factors moderately increased MCNs and their values were $31 \pm 2$ (EGF), $28 \pm 1$ (HB-EGF), $35 \pm 3$ (TGF- $\beta$ ) and $35 \pm 1$ (LIF) compared to $27 \pm 2$ for untreated controls. Treatment of antibodies to cultured embryos reduced their MCNs uniformly; values were $20 \pm 1$ (anti-EGF), $27 \pm 3$ (anti-HBEGF), $18 \pm 1$ (anti-TGF- $\beta$ ) and $20 \pm 1$ (anti-LIF) compared to non-immune IgG-treated controls $(22 \pm 1)$. Interestingly, however, addition of growth factors to the medium modulated hatching of cultured blastocysts. In particular, HB-EGF and LIF profoundly accelerated hatching with complete dissolution of zona, occurring at an early time point, i.e. $36 \mathrm{~h}$ (Fig. 2, hatched bars in respective treatments). The beneficial effect of growth factors on blastocyst hatching could be markedly curtailed by their respective antibodies, but not by non-immune-IgG (Fig. 3), thus indicating that the observed effects are growth factor-specific and developmental event-specific. Besides, addition of HB-EGF increased blastocyst attachment and also markedly increased TB outgrowth (Mishra and Seshagiri, 2000b).

Our unpublished data of northern blot/RT-PCR and immunocytochemical analyses of hamster uterine tissue samples indicate that mRNAs of 
EGF, HB-EGF, TGF- $\beta$ s and LIF are variably expressed on days $1-6$ of pregnancy (day $4=$ time of implantation). Thereafter, the levels fall by days 5-6 of pregnancy. The protein profile of immunoreactive EGF, HB-EGF and LIF is similar to mRNA profile (Mishra, Rao and Seshagiri, unpublished). During estrous cycle, their mRNAs (TGF- $\beta$ ) are maximally expressed on metestrous or diestrous stages, thereby, indicating that the uterine expression of these growth factors is likely to be regulated by progesterone and that the role of estradiol could be minimal (Ramesh, Kondaiah and Seshagiri, unpublished). Immunoreactive HB-EGF and TGF- $\beta$ s could also be localized in blastocysts (Mishra and Seshagiri, 2000b; Ramesh et al., unpublished). We believe that the interesting changing patterns of expression of mRNA and/or immunoreactive protein in the embryo-endometrial tissues for HB-EGF, TGF- $\beta$ and LIF must be crucial for peri-implantation development in hamsters.

The possible autocrine/paracrine effects involving these factors could be brought about either directly or indirectly via inducing the expression of

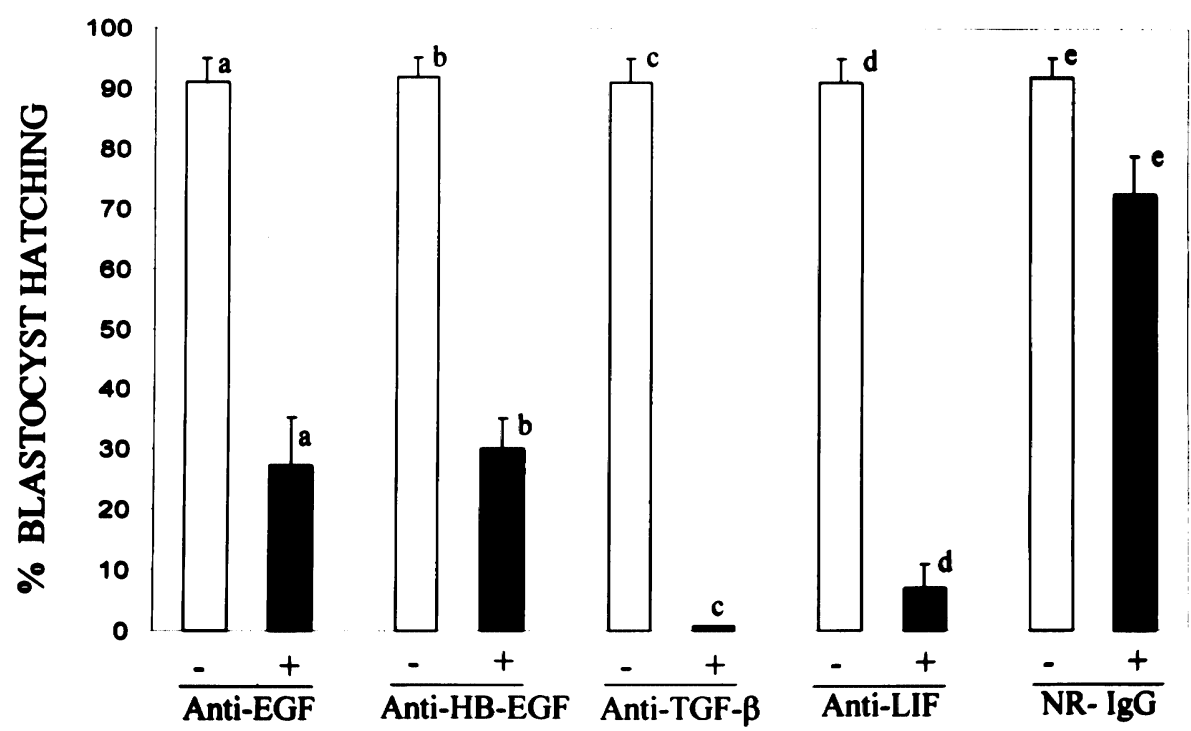

Fig. 3. Influence of antibodies to growth factors, EGF, HB-EGF, TGF- $\beta$ and LIF on hamster blastocyst hatching. Values shown are mean \pm SEM for six replicate experiments each with a minimum of 35-40 embryos per treatment. The bars represent total hatching. Values with identical superscripts $(\mathrm{a}-\mathrm{d})$ differ significantly $(P<0.05)$; while for e, $P>0.05$. Values corresponding to anti-HB-EGF are reproduced from Mishra and Seshagiri (2000b) with permission from Reproductive Health Care Ltd., UK. 


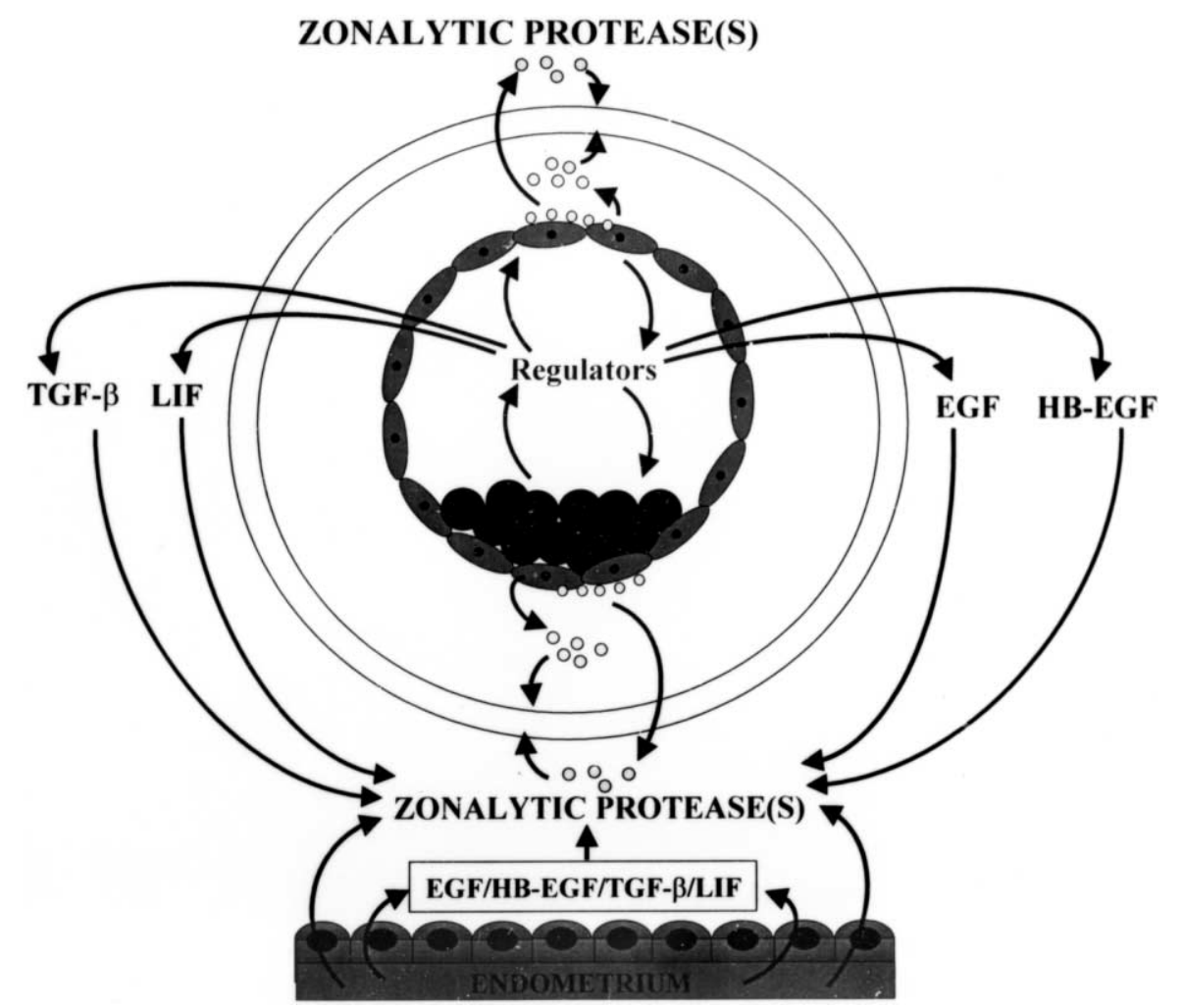

Fig. 4. A hypothetical model showing molecular regulators of embryo-endometrial origin involved in protease-mediated blastocyst hatching. Abbreviations used are epidermal growth factor (EGF), heparin binding-EGF (HB-EGF), transforming growth factor- $\beta$ (TGF- $\beta$ ) and leukemia inhibitory factor (LIF).

other molecular mediators, thereby hastening development. Moreover, growth factors could be influencing/augmenting the embryonic expression of zona lysins (protease) from either mural or polar TE cells (Fig. 4). At this time, we do not know whether the zona lytic activity is cell membrane bound, presumably with TE-projections (Fig. 1; Gonzales et al., 1996), or secreted into the peri-vitelline space for inducing zona lysis (Fig. 4). These exciting cellular and molecular mechanisms remain to be examined in hamster development. Based on what is known in most mammals examined, including humans (Paria and Dey 1990; Das et al., 1994; Kane et al., 1997; Martin et al., 1998; Sargent et al., 1998; Tawada et al., 1999), it is becoming clear that embryonic growth factors have major autocrine/ paracrine roles to play during blastocyst development, differentiation and implantation. 


\section{Conclusion}

The hamster embryo development system, using HECM-2h which supports maximal development of hatched-blastocysts with potential to attach and exhibit TB outgrowth, could provide new avenues for gaining insights into the cellular and molecular regulation of pre-/peri-implantation development. It appears that HB-EGF and LIF profoundly regulate hatching and peri-attachment blastocyst development with other embryo-endometriumderived regulators potentially controlling early development via autocrine and/or paracrine mechanisms.

\section{Acknowledgements}

Financial support from the Department of Science and Technology, New Delhi is gratefully acknowledged. The authors thank Dr M. Klagsbrun, Harvard Medical School, Boston, MA, USA, for kindly providing the HB-EGF antibody; Ms H.S. Lalitha for technical support and Ms M.S. Padmavathi for her help during the preparation of the manuscript.

\section{References}

Ain, R., Seshagiri, P.B., 1997. Succinate and malate improve development of hamster eight-cell embryos in vitro: confirmation of viability by embryo transfer. Mol. Reprod. Dev. 47, 440-447.

Barnett, D.K., Bavister, B.D., 1992. Hypotaurine requirement for in vitro development of golden hamster one-cell embryos into morulae and blastocysts, and production of term offspring from in vitro-fertilized ova. Biol. Reprod. 47, 297-304.

Bavister, B.D., 1995. Culture of preimplantation embryos: facts and artifacts. Hum. Reprod. $1,91-148$.

Bergstrom, S., 1972. Shedding of the zona pellucida of the mouse blastocyst in normal pregnancy. J. Reprod. Fert. 31, 275-277.

Das, S.K., Wang, X.N., Paria, B.C., et al., 1994. Heparin-binding EGF-like growth factor gene is induced in the mouse uterus temporally by the blastocyst solely at the site of its apposition: a possible ligand for interaction with blastocyst EGF-receptor in implantation. Development 120, 1071-1083.

Denker, H.W., 1977. Implantation. The role of proteinases, and blockage of implantation by proteinase inhibitors. Adv. Anat. Embryol. Cell Biol. 53, 3-123.

Denker, H.W., Fritz, H., 1979. Enzymatic characterization of rabbit blastocyst proteinase with synthetic substrates of trypsin-like enzymes. Hoppe Seylers Z. Physiol. Chem. 360, $107-113$.

Evans, C.A., Kennedy, T.G., 1980. Blastocyst implantation in ovariectomized, adrenalectomized hamsters treated with inhibitors of steroidogenesis during the peri-implantation period. Steroids $36,41-52$. 
Gonzales, D.S., Bavister, B.D., 1995. Zona pellucida escape by hamster blastocysts in vitro is delayed and morphologically different compared with zona escape in vivo. Biol. Reprod. 52, 470-480.

Gonzales, D.S., Boatman, D.E., Bavister, B.D., 1996. Kinematics of trophectoderm projections and locomotion in the peri-implantation hamster blastocysts. Dev. Dyn. 205, $435-444$.

Harvey, M.B., Leco, K.J., Arcellana-Panlilio, M.Y., Zhang, X., Edwards, D.R., Schultz, G.A, 1995. Roles of growth factors during peri-implantation development. Mol. Hum. Reprod. 10, 712-718.

Joshi, M.S., Murray, I.M., 1974. Immunological studies of the rat uterine fluid peptidase. J. Reprod. Fertil. 37, 361-365.

Kane, M.T., Bavister, B.D., 1988a. Protein-free culture medium containing polyvinyl alcohol, vitamins and amino acids supports development of eight-cell hamster embryos to hatching blastocysts. J. Exp. Zool. 247, 183-187.

Kane, M.T., Bavister, B.D., 1988b. Vitamin requirements for development of eight-cell hamster embryos to hatching blastocysts in vitro. Biol. Reprod. 39, 1137-1143.

Kane, M.T., Morgan, P.M., Coonan, C., 1997. Peptide growth factors and preimplantation development. Hum. Reprod. Update 3, 137-157.

Kauma, S.W., 2000. Cytokines in implantation. J. Reprod. Fertil. Suppl. 55, 31-42.

Lopata, A., Hay, D.L., 1989. The potential of early human embryos to form blastocysts, hatch from their zona and secrete hCG in culture. Hum. Reprod. 4, 87-94.

Magli, M.C., Gianaroli, L., Ferraretti, A.P., Fortini, D., Aicardi, G., Montanaro, N., 1998. Rescue of implantation potential in embryos with poor prognosis by assisted zona hatching. Hum. Reprod. 13, 1331-1335.

Martin, K.L., Barlow, D.H., Sergent, I.L., 1998. Heparin-binding epidermal growth factor significantly improves human blastocyst development and hatching in serum-free medium. Hum. Reprod. 13, 1645-1652.

Massip, A., Mulnard, J., 1980. Time-lapse cinematographic analysis of hatching of normal and frozen-thawed cow blastocysts. J. Reprod. Fertil. 58, 475-478.

McKiernan, S.H., Bavister, B.D., 1990. Environmental variables influencing in vitro development of hamster 2-cell embryos to the blastocyst stage. Biol. Reprod. 43, 404-413.

Menino, A.R. Jr., Williams, J.S., 1987. Activation of plasminogen by the early bovine embryo. Biol. Reprod. 36, 1289-1295.

Mishra, A., Seshagiri, P.B., 1998. Successful development in vitro of hamster 8-cell embryos to 'zona-escaped' and attached blastocysts: assessment of quality and trophoblast outgrowth. Reprod. Fertil. Dev. 10, 413-420.

Mishra, A., Seshagiri, P.B., 2000a. Evidence for the involvement of species-specific embryonic protease in zona dissolution of hamster blastocysts. Mol. Hum. Reprod. 6, 10051012.

Mishra, A., Seshagiri, P.B., 2000b. Heparin binding-epidermal growth factor improves blastocyst hatching and trophoblast outgrowth in the golden hamster. Reprod. BioMed. Online 1, 87-95.

Paria, B.C., Dey, S.K., 1990. Preimplantation embryo development in vitro: cooperative interactions among embryos and role of growth factors. Proc. Natl. Acad. Sci. USA. 87, $4756-4760$.

Perona, R.M., Wassarman, P.M., 1986. Mouse blastocysts hatch in vitro by using a trypsin-like proteinase associated with cells of mural trophoectoderm. Dev. Biol. 114, $42-52$. 
Sargent, I.L., Martin, K.L., Barlow, D.H., 1998. The use of recombinant growth factors to promote human embryo development in serum-free medium. Hum. Reprod. 13, 239-248.

Sawada, H., Yamazaki, K., Hoshi, M., 1990. Trypsin-like hatching protease from mouse embryos: evidence for the presence in culture medium and its enzymatic properties. J. Exp. Zool. 254, 83-87.

Schini, S.A., Bavister, B.D., 1988. Two-cell block to development of cultured hamster embryos is caused by phosphate and glucose. Biol. Reprod. 39, 1183-1192.

Seshagiri, P.B., Bavister, B.D., 1989a. Glucose inhibits development of hamster 8-cell embryos in vitro. Biol. Reprod. 40, 599-606.

Seshagiri, P.B., Bavister, B.D., 1989b. Phosphate is required for inhibition by glucose of development of hamster 8-cell embryos in vitro. Biol. Reprod. 40, 607-614.

Seshagiri, P.B., Bavister, B.D., 1991a. Glucose and phosphate inhibit respiration and oxidative metabolism in cultured hamster eight-cell embryos: evidence for the 'Crabtree effect'. Mol. Reprod. Dev. 30, 105-111.

Seshagiri, P.B., Bavister, B.D., 1991b. Relative developmental abilities of hamster 2- and 8-cell embryos cultured in hamster embryo culture medium-1 and -2. J. Exp. Zool. 257, $51-57$.

Seshagiri, P.B., Hearn, J.P., 1993. In vitro development of in vivo produced rhesus monkey morulae and blastocysts to hatched, attached, and post-attached blastocyst stages: morphology and early secretion of chorionic gonadotrophin. Hum. Reprod. 8, 279-287.

Seshagiri, P.B., Mishra, A., Krishnamurthy, G., 1999. Regulation of development of peri-attachment embryos: comparative studies in rodents. In: Gupta, S.K. (Ed.), Reproductive Immunology. Narosa Publishing Home, New Delhi, pp. 110-120.

Simon, C., Gimeno, M.J., Mercader, A., Frances, A., Velasco, J.G., Remohi, J., Polan, M.L., Pellicer, A., 1996. Cytokines-adhesion molecules-invasive proteinases. The missing paracrine/autocrine link in embryonic implantation? Mol. Hum. Reprod. 2, 405-424.

Surani, M.A.H., 1975. Zona pellucida denudation, blastocyst proliferation and attachment in the rat. J. Embryol. Exp. Morphol. 33, 343-353.

Tawada, H., Higashiyama, C., Takano, H., et al., 1999. The effects of heparin-binding epidermal growth factor-like growth factor on preimplantation-embryo development and implantation in the rat. Life Sci. 64, 1967-1973.

Vu, T.K.H., Liu, R.W., Haaksma, C.J., Tomasek, J.J., Howard, E.W., 1997. Identification and cloning of the membrane-associated serine protease, hepsin, from mouse preimplantation embryos. J. Biol. Chem. 272, 31315-31320. 